\title{
Thermodynamics and structure of $\mathrm{Np}(\mathrm{V})$
}

\section{complexes with formate. A spectroscopic}

and theoretical study.

Martin M. Maiwald ${ }^{1 *}$, Kathy Dardenne ${ }^{2}$, Jörg Rothe ${ }^{2}$, Andrej Skerencak-Frech², Petra J. Panak ${ }^{1,2}$

1) Ruprecht Karls Universität Heidelberg, Physikalisch-Chemisches Institut, Im Neuenheimer Feld 253, D-69120 Heidelberg, Germany

2) Karlsruher Institut für Technologie (KIT), Institut für Nukleare Entsorgung (INE), D-76344 EggensteinLeopoldshafen, Germany

*e-mail:m.maiwald@pci.uni-heidelberg.de

\section{Supporting Information}

\section{Figures}
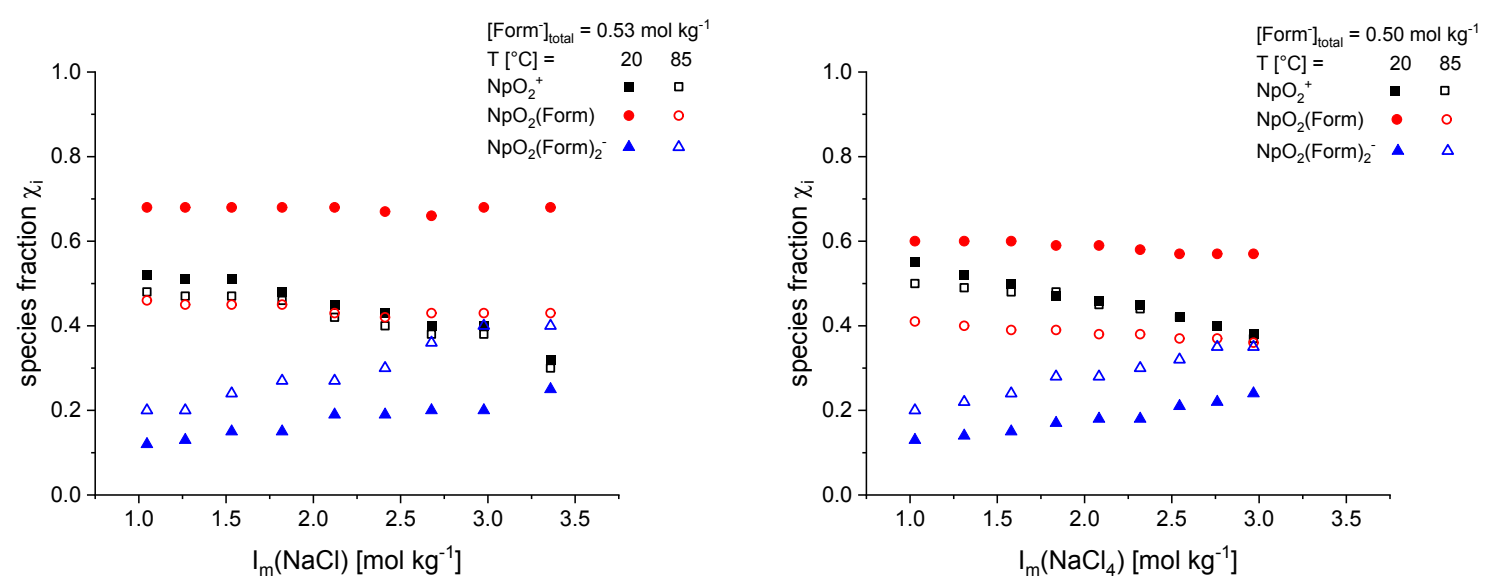

Figure S 1: Experimental species distribution of $\mathrm{NpO}_{2}(\text { Form })_{n}{ }^{1-n}(n=0-2)$ complexes as a function of the ionic strength $I_{m}$ at a fixed ligand concentration of [Form $]_{\text {total }}=0.5 \mathrm{~mol} \mathrm{~kg}^{-1} . \mathrm{T}=20^{\circ} \mathrm{C}$ (full symbols) and $85^{\circ} \mathrm{C}$ (open symbols). 


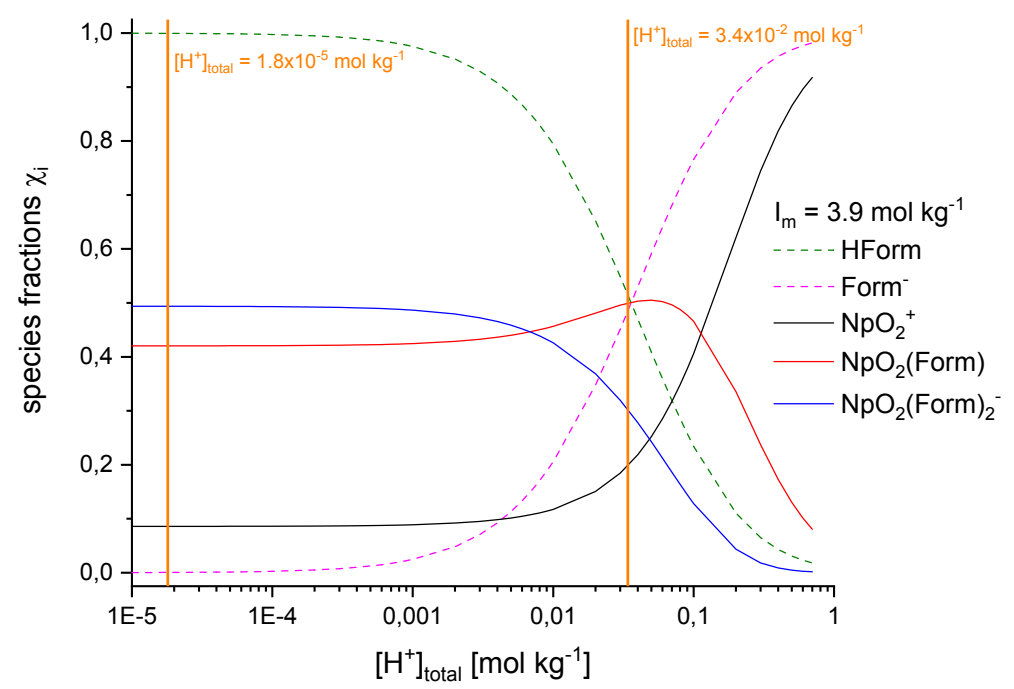

Figure S2: Species distribution of formate and the $\mathrm{NpO}_{2}(\text { Form })_{n}{ }^{1-n}(n=1,2)$ complexes as a function of the total proton concentration $\left[\mathrm{H}^{+}\right]_{\text {total }}$ at $[\text { Form }]_{\text {total }}=0.6 \mathrm{~mol} \mathrm{~kg}^{-1}$ and $\mathrm{I}_{\mathrm{m}}=3.9 \mathrm{~mol} \mathrm{~kg}^{-1}$.

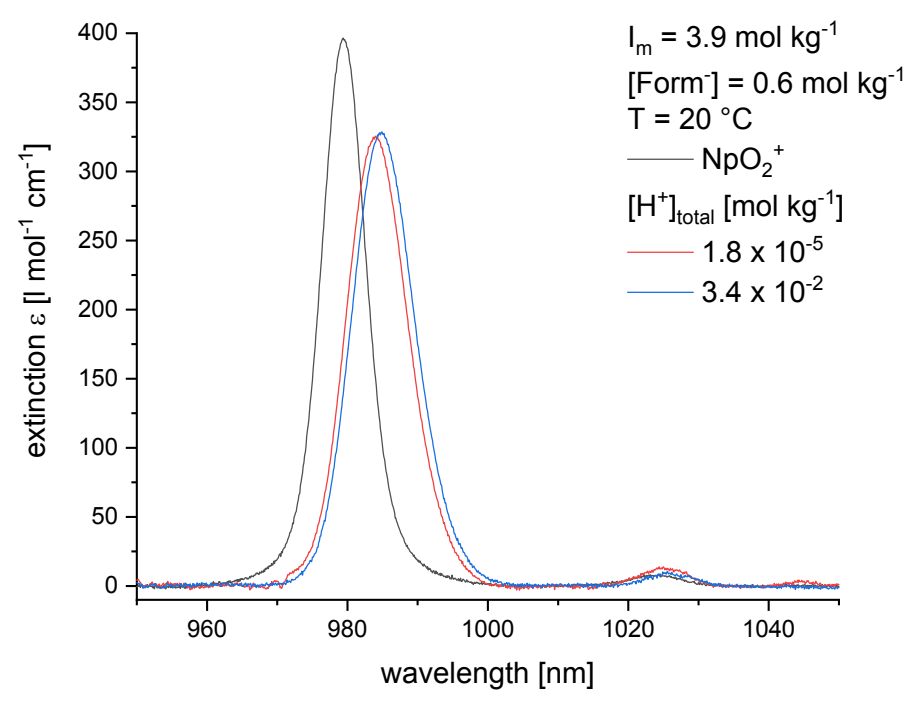

Figure S 3: Absorption spectra of the $\mathrm{Np}(\mathrm{V})$ EXAFS samples at two different total proton concentrations $\left[\mathrm{H}^{+}\right]_{\text {total }}$ at $[\text { Form- }]_{\text {total }}$ $=0.6 \mathrm{~mol} \mathrm{~kg}^{-1}$ and $\mathrm{I}_{\mathrm{m}}=3.9 \mathrm{~mol} \mathrm{~kg}^{-1}$. 


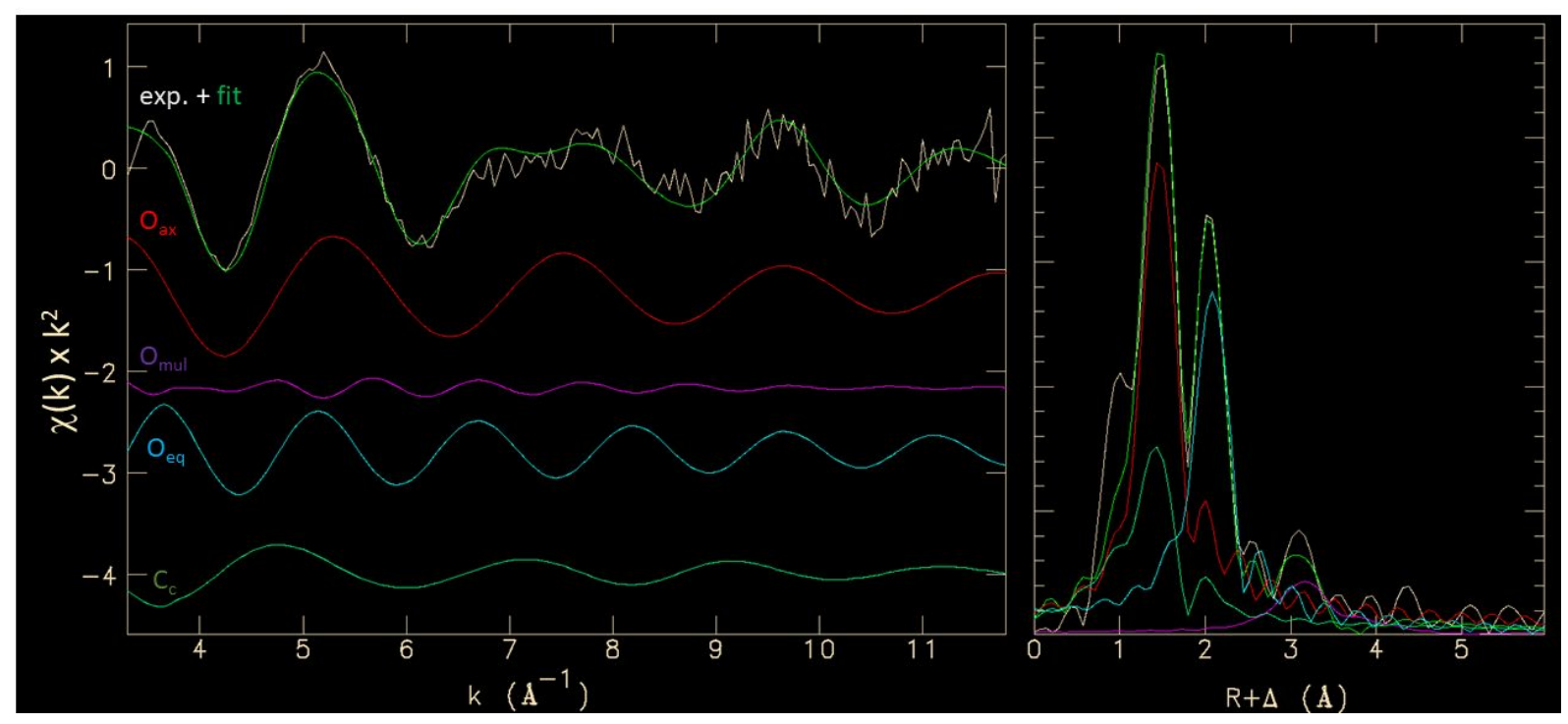

Figure S 4: Deconvolution of the $\mathrm{k}^{2}$-weighted fits of the $\mathrm{Np}-\mathrm{L}_{3}$ EXAFS spectrum of $\mathrm{Np}(\mathrm{V})$ in the presence of formate. $\left[\text { From }^{-}\right]_{\text {total }}=0.6 \mathrm{~mol} \mathrm{~kg}^{-1},\left[\mathrm{H}^{+}\right]_{\text {total }}=1.8 \times 10^{-5} \mathrm{~mol} \mathrm{~kg}^{-1}$.

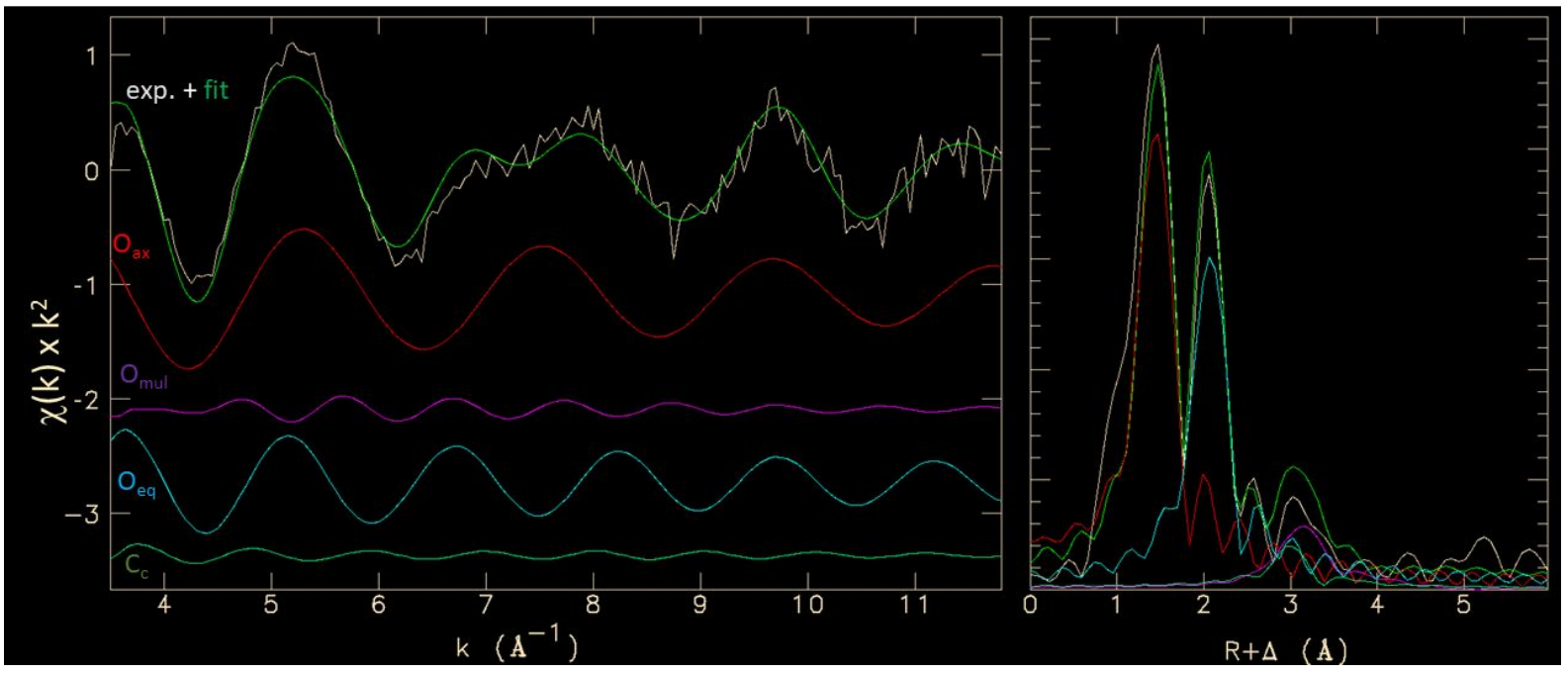

Figure S 5: Deconvolution of the $\mathrm{k}^{2}$-weighted fits of the $\mathrm{Np}-\mathrm{L}_{3}$ EXAFS spectrum of $\mathrm{Np}(\mathrm{V})$ in the presence of formate. $[\text { From }]_{\text {total }}=0.6 \mathrm{~mol} \mathrm{~kg}^{-1},\left[\mathrm{H}^{+}\right]_{\text {total }}=3.4 \times 10^{-2} \mathrm{~mol} \mathrm{~kg}^{-1}$. 

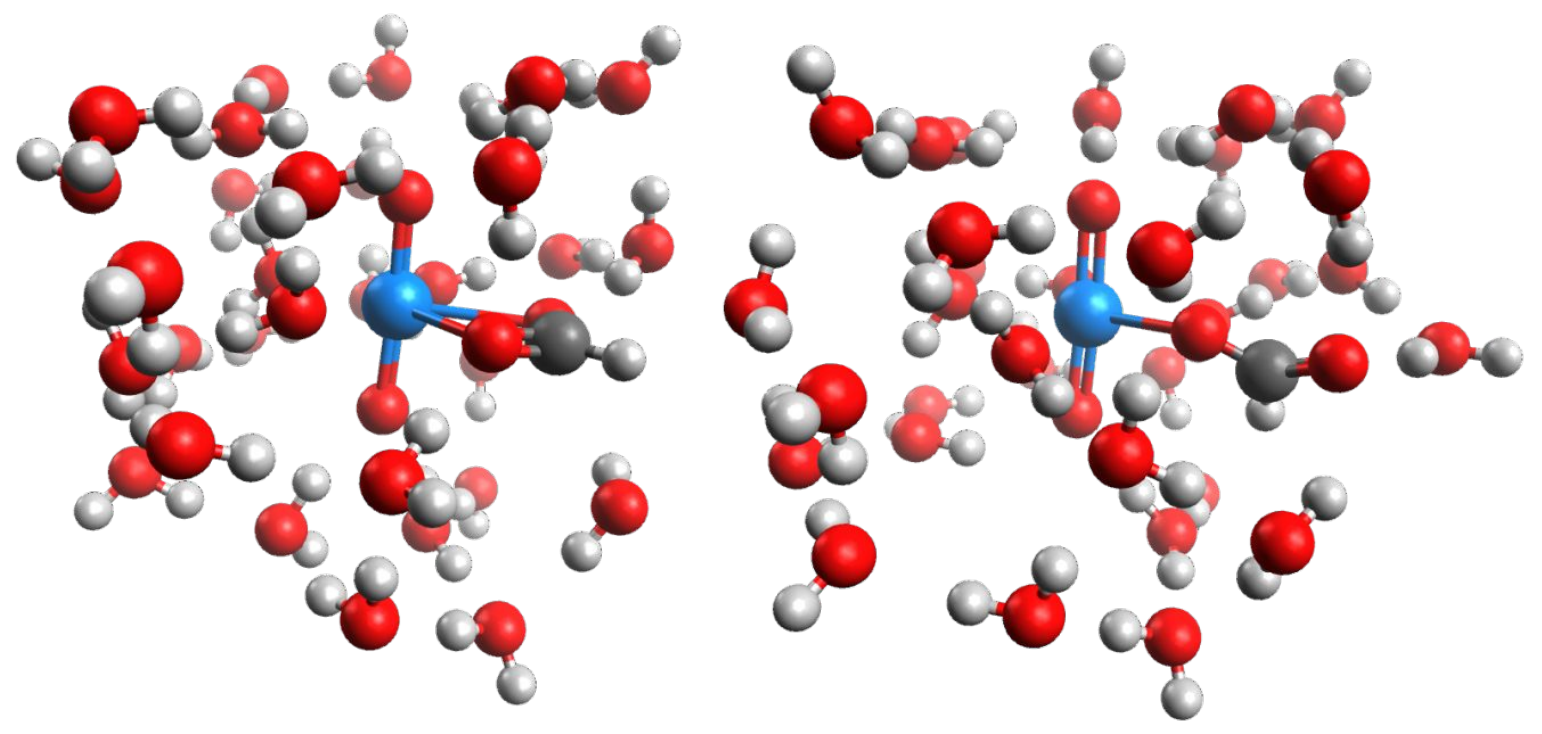

Figure S 6: Structures of the optimized conformers of the $\mathrm{NpO}_{2}$ (From) complex with second hydration shell. (left) bidentate coordination mode of formate; (right) monodentate coordination mode of formate.
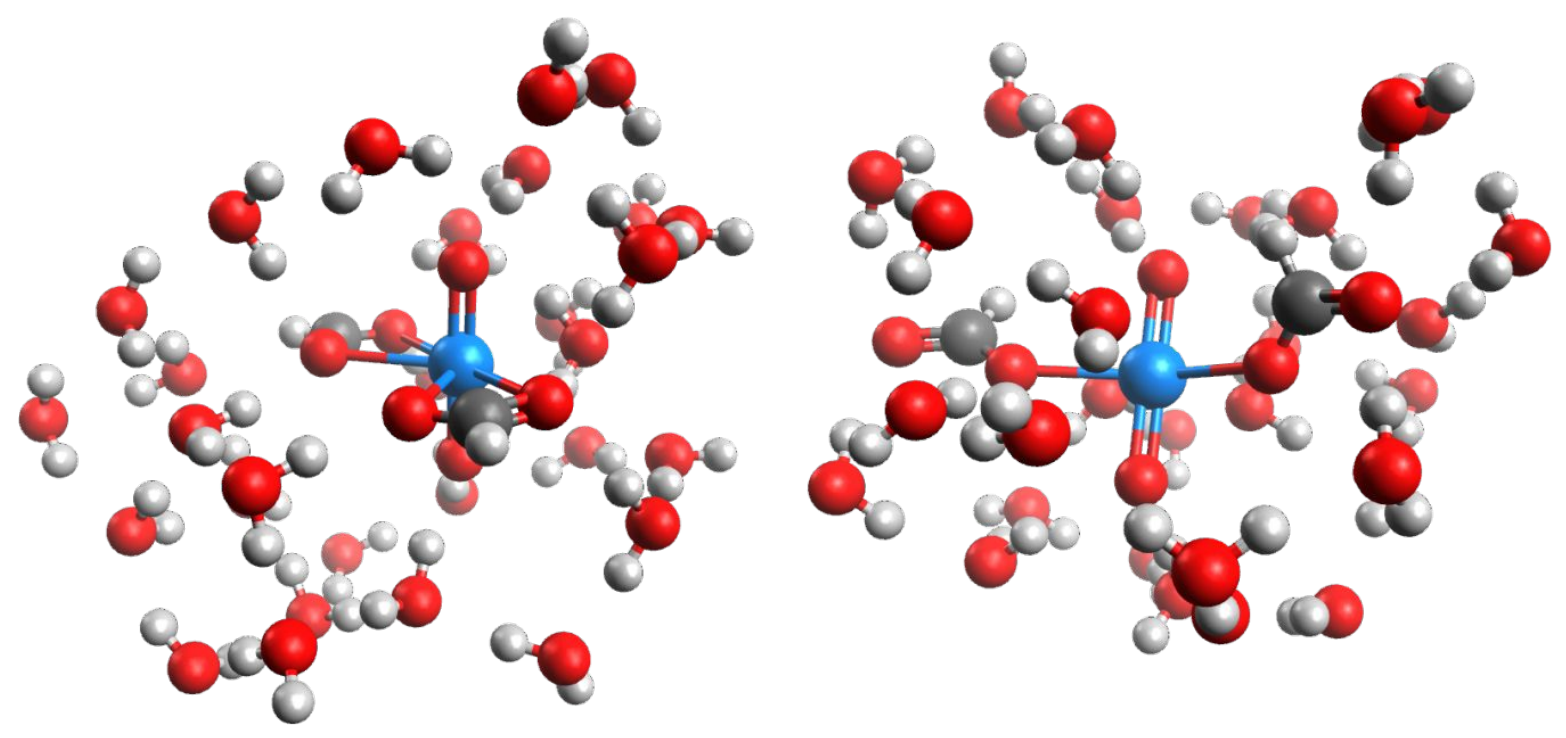

Figure S 7: Structures of the optimized conformers of the $\mathrm{NpO}_{2}(\text { From })_{2}^{-}$complex with second hydration shell. (left) bidentate coordination mode of formate; (right) monodentate coordination mode of formate. 